\title{
Aerosol Gemcitabine
}

National Cancer Institute

\section{Source}

National Cancer Institute. Aerosol Gemcitabine. NCI Thesaurus. Code C153133.

An aerosol inhalation formulation containing gemcitabine (GCB), a broad-spectrum antimetabolite and deoxycytidine analogue, with potential antineoplastic activity. Upon inhalation via a nebulizer, GCB is converted intracellularly by deoxycytidine kinase to its active metabolites difluorodeoxycytidine di- and triphosphate (dFdCDP, dFdCTP). dFdCDP inhibits ribonucleotide reductase (RNR), thereby decreasing the deoxynucleotide pool available for DNA synthesis; dFdCT P competes with deoxycytidine triphosphate (dCT P) and is incorporated into DNA, resulting in DNA strand termination and the induction of apoptosis of lung tumor cells. GCB administration directly into the lungs via aerosol yields higher concentrations of GCB locally than can be achieved by systemic GCB administration, potentially reducing systemic toxicity. 